\title{
Percent Predicted Maximal Expiratory Pressure
}

National Cancer Institute

\section{Source}

National Cancer Institute. Percent Predicted Maximal Expiratory Pressure. NCI

Thesaurus. Code C135495.

The greatest amount of pressure that can be generated by exhaling against a

mouthpiece, which is a measure of the strength of respiratory muscles expressed as a proportion of the predicted normal value. 